\title{
Endüstriyel Atık Katkılı Kum Zeminlerin Geçirimsizlik Davranışının Araştırılması
}

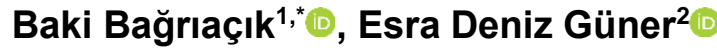 \\ ${ }^{1}$ Çukurova Üniversitesi, Mühendislik Fakültesi, Inşaat Mühendisliği Bölümü, 01330, Adana. \\ ${ }^{2}$ Çukurova Üniversitesi, Mühendislik Fakültesi, Çevre Mühendisliği Bölümü, 01330, Adana.
}

\section{Özet}

Yeniden kullanım potansiyeline sahip olan, endüstriyel atıkların yeni alternatif yöntemlerle değerlendirilmesi oldukça önemlidir. Arıtma tesisi çamurları ve uçucu kül faydalı geri kullanım potansiyeli olduğu bilinen endüstriyel atıklardandır. Bu endüstriyel atıkların yararl yeniden kullanımları, çevresel kirliliğin azaltılması, depolama maliyetlerini düşürülmesi, sınırlı olan doğal kaynakların kullanımının azaltılması ve yeni nesil malzeme sağlanması ile kuruluşların ve ülkenin ekonomik gelişimine katkı sağlayabilecektir. Üzerine yapı inşa edilen zemin ve kaya ortamların jeolojik kökenleri çok değişken bir yapıya sahiptir ve farklı tipteki jeolojik malzemeler tasarım açısından farklı çözümler gerektirir. Zayı zemin şartlarına sahip sahalarda inşa edilecek yapılarda geleneksel temel inşaatı yöntemleri pahaliya mal olmakta ve ekonomikliğini kaybetmektedir. Bu tür zeminlerde geleneksel yöntemler ile yapılan inşaat maliyetinin yüksek olması, çevre faktörlerinin oluşturduğu sayısız sıkıntılar bulunmaktadır. Günümüzde farklı katkı malzemeleri ile zeminlerin nasıl davranış gösterdiği oldukça önem kazanmıştır. Bu çalışmada, endüstriyel atık olan içme suyu arıtma tesisi çamurları ile uçucu kül malzemelerin kumlu zemin ortamında geçirimsizlik davranışları incelenmiştir. Çalışma kapsamında kum zemine, \%2, \%4, \%6, \%8, \%10, \%12, \%14, \%16, \%18, \%20, \%22 oranlarında ağırlıkça içme suyu arıtma çamuru ve uçucu kül eklenmiștir. Hazırlanan karıșımların geçirimlilik davranışları, küçük ölçekli model deneyler yardımı ile katkı oranlarına ve zamana bağlı olarak araştırılmıştır. Elde edilen sonuçlara göre, her iki endüstriyel atık malzemelerin de kumlu zeminlerde geçirimsizliğini kayda değer oranda artırdı̆̆ görülmüștür. Endüstriyel atık malzemelerin \%2 oranında katıldiğında 106 ve \%22 oranında katıldı̆̆ında ise 1691 kata varan artışlar tespit edilmiştir.

\section{Anahtar Sözcükler}

Zemin İyileştirme, Atık Geri Dönüşümü, Atık Çamur, Uçucu Kül, Katı Atık Yönetimi

\section{Investigation of Permeability Behavior of Sandy Soils Mixed with Industrial Waste}

\begin{abstract}
It is very important to evaluate the industrial wastes, which have the potential to be reused with new alternative methods. Treatment plant sludges and fly ash are industrial wastes known to have the potential for beneficial reuse. The useful reuse of these industrial wastes will contribute to the economic development of the organizations and the country by reducing environmental pollution, reducing storage costs, reducing the use of limited natural resources and providing new generation materials. The geological origins of the ground and rock environments on which the structure is constructed have a very variable structure and different types of geological materials require different solutions in terms of design. Conventional foundation construction methods are expensive and lose their economy in the buildings to be constructed in areas with poor ground conditions. In recent years, due to the high cost of construction with traditional methods, the numerous problems caused by environmental factors and the difficulties in overcoming them, the use of on-site soil remediation methods on the poor soil has gained importance. In this study, the impermeability behaviors of sludges and fly ash materials of industrial waste drinking water treatment plant were investigated. Within the scope of the study, drinking water treatment sludge and fly ash were added to sand ground in $2 \%, 4 \%, 6 \%, 8 \%, 10 \%, 12 \%, 14 \%, 16 \%, 18 \%, 20 \%$, 22\%. The permeability behavior of the prepared mixtures was investigated with the help of small scale model experiments depending on the contribution rates and time. According to the results obtained, it is observed that both industrial waste materials significantly increase the impermeability of sandy soils. Experimental data indicates s that the increases of up to 106 times when industrial waste materials were added at $2 \%$ and up to 1691 times when $22 \%$ were added.
\end{abstract}

$\underline{\text { Keywords }}$

Soil Improvement, Waste Recycling, Waste Mud, Fly Ash, Solid Waste Management

\section{Giriş}

Hızlı bir büyüme eğilimi içinde olan endüstriyel faaliyetler ekonomik gelişme için zorunlu olsa da, açığa çıkan endüstriyel atıkların miktarının önemli boyutlarda olması endüstriyel atık problemini günümüzde önemli sorunlardan biri haline dönüştürmüştür. 
Artan endüstriyel atık malzemelerin tüketim yöntemi olarak tekrar kullanılması, azalan atık depolama imhası, bakir kaynak kullanımının azaltılması ve azalan sera gazı emisyonları gibi çeşitli çevresel faydalara sahiptir (Zacco vd. 2014). Endüstriyel atık malzemelerin doğrudan kullanımı, özellikle uçucu kül, atık çamur gibi tehlikeli endüstriyel atıkların tüketilmesi için istenen yöntemlerden biridir ve doğrudan kullanım yoluyla atık malzemelerin tüketimi düşük maliyete sahip olduğundan, endüstriyel şirketler için önde gelen stratejilerden biridir (Dindi vd. 2019). Geri dönüşümde kazanılan deneyimler, atıkların yararlı ürünlere dâhil edilmesi yoluyla geri dönüşümün mümkün olduğunu, ancak bu atıkların etkin teknolojilerle geri dönüşümü için endüstriyel ölçekte çözümlere ulaşma eylemlerinin çok önemli olduğunu göstermektedir (Mazzoli ve Moriconi 2014).

Endüstriyel atıklar içerisinde, yeniden kullanım potansiyeli üzerine yapılan çalışmaların oldukça yetersiz olduğu bilinenlerden bir tanesi de arıtma çamurlarıdır. İçme suyu arıtma çamuru (İSAÇ), evsel ve endüstriyel arıtma tesislerinde istenilen kalitede suyu elde etmek için uygulanan arıtma prosesinde büyük miktarlarda üretilen bir yan üründür (Feng vd. 2014; Zhang vd. 2009).

Arıtma tesisleri kaliteli, sağlıklı suya erişim veya atık suların yeniden deşarjı/kullanım için vazgeçilmez konumdadır. Gelişmişliğin bir göstergesi olan su arıtma tesislerinin sayısı ve kapasitesi de nüfus artışına ve şehirleşmeye bağlı olarak artmaktadır. TÜİK verilerine göre, 2016 yılı itibari ile içme ve kullanma suyu arıtma tesisi sayısı 519 olup, su arıtma tesislerinde yaklaşık 3.350.389 bin m3/yıl su arıtılmıştır. Fakat, içme suyu arıtma tesislerinde oluşan toplam çamur miktarları ve özelliklerini içeren kapsamlı bir envanter bulunmamaktadır. Ancak bu tesislerde uygulanan proses gereğince hemen hemen tüm aşamalarda atık çamur oluşmaktadır (TÜİK 2019). Arıtma tesisinden çıkan çamur hem bölgesel hem de evrensel boyutta büyük bir sorun oluşturmaktadır.

İSAÇ'nin miktarı ve kalitesi, arıtılan suyun kalitesinin yanı sıra arıtma işlemlerine bağlıdır. Temin edilen su temizse, daha az arıtma aşaması gerekir. Ancak, kaynak suyunun kirli olması veya istenilen su kalitesinin artması ile ileri arıtma prosesleri uygulanır ve oluşan çamurun miktarı ve içeriği de değişim gösterir. Tipik bir içme suyu arıtma tesisi prosesi kimyasal koagülasyon (pıhtılaşma) ve flokülasyon (yumaklaştırma), çökeltme, filtrasyon ve dezenfeksiyon olarak 5 ana prosesten oluşmaktadır. Bu prosesler de en önemli aşama pıhtılaştırma aşaması olup pıhtılaştırıcı olarak çeşitli koagülantlar kullanılmaktadır. Kullanılan bu kimyasal pıhtılaştırıcılar, çok küçük parçacıkları birbirine yapıştırarak koloidal ve askıdaki katı maddelerin tümünü floklar haline getirilmesi ile kendi ağırlığı ile çökebilen büyük parçacıkların oluşmasına neden olur. Daha sonra çökeltme ve süzme yoluyla suya kirlilik veren maddeler oluşan floklar (çamur) ile sudan uzaklaştırılır (Ahmad vd. 2016; Jung vd. 2016). İSAÇ’nin üretimindeki artışın tersine bertarafı oldukça sınırlı olup bertarafı ve maliyeti ile ilişkili endişeler de artmaktadır. Son yıllarda, geleneksel bertaraf yöntemleri dışında, çevre dostu, ekonomik ve sürdürülebilir atık yönetimi ile çamur bertaraf seçenekleri araştırılmaktadır. Ayrıca, hammadde değeri göz önüne alındığında ekonominin gereksinimi olan malzemelerin üretilmesinde arıtma çamurları (AÇ) gibi atıkların yeniden değerlendirilmesi (geri dönüşüm) önem kazanmaktadır (Hacısalihoğlu 2008). İSAÇ için tarım topraklarında gübre olarak kullanımı, enerji geri kazanımı ile yakma, endüstriyel işlemler veya katı atık depolama tesislerinde depolanması sıklıkla kullanılan yöntemlerdendir (Jensen ve Jepsen 2005; Santana vd. 2014). Katı atık tesislerinde depolama çevre duyarlılığının artması ve yasal kısıtlamalardan dolayı giderek daha az tercih edilmektedir (URL-1 1991; URL-2 1999). Ayrıca, gübre olarak tarım uygulamalarında kullanımı da yaygın bir yöntemdir. Fakat çevre için daha sıkı düzenlemeler ve sosyal kaygılar nedeniyle AÇ’ın tarımsal bertarafında giderek daha fazla zorlanılmaktadır (Yang vd. 2015). Ek olarak, yakma alternatifi de bulunmaktadır (Wang vd. 1992). Bu yöntemlerin çeşitli dezavantajları ve ek maliyeti nedeniyle, AÇ'nin nihai olarak bertarafı için yeni alternatif yöntemler son y1llarda küresel olarak önemli bir konu haline gelmektedir (Nimwinya vd. 2016; Garrido-Baserba vd. 2015; Dassanayake vd. 2015; Yang vd. 2015).

Endüstriyel bir sorun olan ve miktarca fazla çıkan bir diğer endüstriyel atık ise uçucu küldür (UK). UK, kömürle çalışan elektrik üretim tesislerinden kaynaklanan toplam yanma tortularının yaklaşık \%60-88'ini oluşturan bir yan üründür ve kömürün tamamen yanmadığı mineralinden dolayı çevresel bir kirletici olarak kabul edilir (Dindi vd. 2019; Ahmaruzzaman 2010). UK'nın İSAÇ'a benzer şekilde çevresel kirliliğe neden olmasından dolayı depolama ve bertaraf sorunu bulunmakta ve yeniden değerlendirilmesi için alternatif çözümlerin üzerinde çalışılması çok önemlidir. UK için iyi bilinen ve yaygın olarak kullanılan bertaraf yöntemi, atık depolama alanlarında depolanmasıdır. Katı atıkların atık depolama sahalarında bertaraf edilmesi günden güne daha fazla depolama alanına ihtiyaç duymakta ve ayrıca ciddi çevresel sorunlara yol açan ilave karbon emisyonlarına neden olmaktadır. Sonuç olarak, bu yöntem son zamanlarda daha az çekici hale gelmektedir (Basu vd. 2009; Ahmaruzzaman 2010; Xie vd. 2019).

$\mathrm{Bu}$ atıkların tekrar kullanılması üzerine yapılan çalışmalar, tarımdan mühendisliğe kadar geniş bir alanı kapsamaktadır. İnşaat uygulamaları atık malzemelerin kısmen veya tamamen değerlendirilmesi için çok büyük bir fırsat sunabilmektedir (Velasco vd. 2014). İSAÇ için, çimento klinker üretimi (Rodríguez vd. 2011), hafif agrega üretimi (Hu vd. 2013), harç (Frías vd. 2014), beton (Tantawy 2015), tuğla (Benlalla vd. 2015), yol kaplamaları (Ghazawi vd. 2015), geoteknik (Caniani vd. 2013), seramik üretiminde (Amin vd. 2018) değerlendirilmesi üzerine çok sayıda deneysel çalışma literatürde yer almıştır. UK'nın yeniden kullanımı ve bertarafı için ağırlıklı olarak, inşaat sektöründe, kullanılan hammadde malzemelerinin ikame malzemesi olarak UK kullanım potansiyeli üzerine yapılmıştır (Yao vd. 2015; Dabhade 2014). UK'nın puzolanik özellikleri, beton ve diğer bina uygulamalarında çimento değişimi için uygundur (González vd. 2009). UK, klorür iyonları gibi agresif ajanların girişini azaltarak betonun uzun vadeli dayanıklılık özelliklerini iyileştirebilir (Nath ve Sarker 2011). Ren ve Sancaktar (2019), lastik uygulamaları için sentetik kauçukta dolgu maddesi olarak UK kullanımı üzerinde çalışmışlardır. 
Sun vd. (2019), sodyum silikat aktifleştirilmiş uçucu kül ve metakaolin jeopolimerlerinin özelliklerinin zamana bağlı değerlendirilmesi üzerine araştırma yürütmüşlerdir. Hadi vd. (2018), UK'nın bazlı jeopolimer harç özellikleri üzerinde çalışma yapmışlardır. Bu atıkların ekonomik ve çevresel açıdan problemlere neden olmaları nedeniyle yoğun olarak çalışılsa da, miktarca fazla üretildiği için alternatif yöntemlerinin geliştirilmesini zorunlu kılmaktadır. Zemin üzerine inşa olunan yapıların temelleri altında taşıyıcı tabaka olarak bütün inşaat projelerinde karşımıza çıkmaktadır. Zeminler birbirinden farklı özelliklere sahiptir ve zeminin mühendislik özellikleri de zeminin cinsi yanında arazi koşullarına bağlı olarak (sıkılık derecesi, su muhtevası, konsolidasyon basıncı, yükleme ve drenaj koşulları gibi) geniş bir aralık içinde değişebilmektedir. Buna bağlı olarak, inşaat sahasında karşılaşılan zeminler her zaman istenilen özelliklere sahip olmayabilirler. İnşaat yerinin değiştirilmesi veya istenilen özelliklere sahip olmayan zeminlerin atılarak yerine elverişli zeminlerin kullanılması ise, teknolojik ve ekonomik nedenlerle çoğu kere uygun çözümler olarak kabul edilmemektedir. Bu gibi durumlarda, arazideki zemin tabakalarının özelliklerinin iyileştirilmeye çalışılması ve/veya usulüne uygun olarak yerleştirilmiş ve sıkıştırılmış toprak dolgular inşası yoluna başvurulmaktadır.

Katkı malzemeleri ile zemin iyileştirmesi, derin iyileştirme yöntemlerine alternatif olarak geliştirilmiş bir 1slah yöntemidir. Bu yöntem, ekonomik olması ve pratik uygulama kolaylığı ile dünyada yaygın olarak kullanılmaktadır. Özellikle demir ve kara yolu dolgusu, çok katlı olmayan binalar gibi hafif yapıların altındaki zayıf zeminlerin iyileştirilmesinde kullanılmaktadır-

Zemine katkı maddeleri katarak yapılan iyileştirme son yıllarda yaygın olarak kullanılan ve bilimsel açıdan birçok araştırmacı tarafından incelenen yöntemdir (Tosun 1999; Aldaood vd. 2014; Mahvash vd. 2017; Cristelo vd. 2013; Santos vd. 2011). Zemin iyileştirmesi için kullanılacak katkı maddeleri, zemin özellikleri ve iyileştirme yapılmasındaki amaçla doğrudan ilgilidir. Bu yöntem zemine belli oranlarda katkı malzemeleri karıştırılıp sıkıştırma yapılarak uygulanır ve taneler arasında bağ oluşturarak zeminin mukavemet kazanması sağlanır. (Uzuner 2000). Katkı maddeleri olarak; kireç, çimento, bitüm, uçucu kül, reçine gibi maddeler kullanılmaktadır. Çimento, kum-çakıl gibi taneli zeminlerde iyi sonuç vermektedir.

Literatürde bulunan çalışmalar incelendiğinde, geçirimliliği yüksek olan kum zeminlerin, geçirimsizliğinin artırılması gereken durumlar için endüstriyel atıkların kullanımına rastlanmadığı belirlenmiştir. Bu nedenle çalışmada; suya geçirgen zeminlerin (kum zemin) permeabilite değerlerinin, farklı endüstriyel atık malzemeler ile değişimi incelenmiştir. Bu çalışma kapsamında, UK ve İSAÇ’nın \%2, \%4, \%6, \%8, \%10, \%12, \%14, \% 16, \%18, \%20 ve \%22 oranlarında ilavesiyle numuneler hazırlanmıştır. Hazırlanan bu numuneler, küçük ölçekli modeller ile permeametre deneyi yapılarak katkı oranlarına ve zamana bağlı olarak permeabilite değerleri belirlenmiştir.

\section{Materyal ve Metot}

\subsection{Materyal}

Çalışmada, Adana'da nehir yatağından alınan kumlu zemin kullanılmıştır. İSAÇ ise Adana'da bulunan içme suyu arıtma tesisinden temin edilmiştir. Çukurova Üniversitesi zemin mekaniği laboratuvarında etüvde kurutulmuş kum numuneleri üzerinde deneyler yapılmıştır. Araştırmada kullanılan kum zemin ve katkı maddelerinin dane dağılımları belirlenmiştir. Elek analizi yapılan kumlu zemin, TS 1500 standardına (URL-3 2000) göre kötü derecelenmiş temiz kum (SP) olarak sınıflandırılmıştır. Elek analizi sonuçlarına göre hazırlanmış dane dağılımı grafiği Şekil 1'de verilmiştir. Ayrıca kum zeminin, dane birim ağırlığı $26.80 \mathrm{kN} / \mathrm{m}^{3}$, minimum kuru birim ağırlık - maksimum kuru birim ağırlık ve deneylerde kullanılan kum sıkılığı $\left(\mathrm{D}_{\mathrm{r}}\right)$ sırasıyla, $15.03 \mathrm{kN} / \mathrm{m}^{3}, 17.06 \mathrm{kN} / \mathrm{m}^{3}$ ve $\% 40$ olarak belirlenmiştir. 


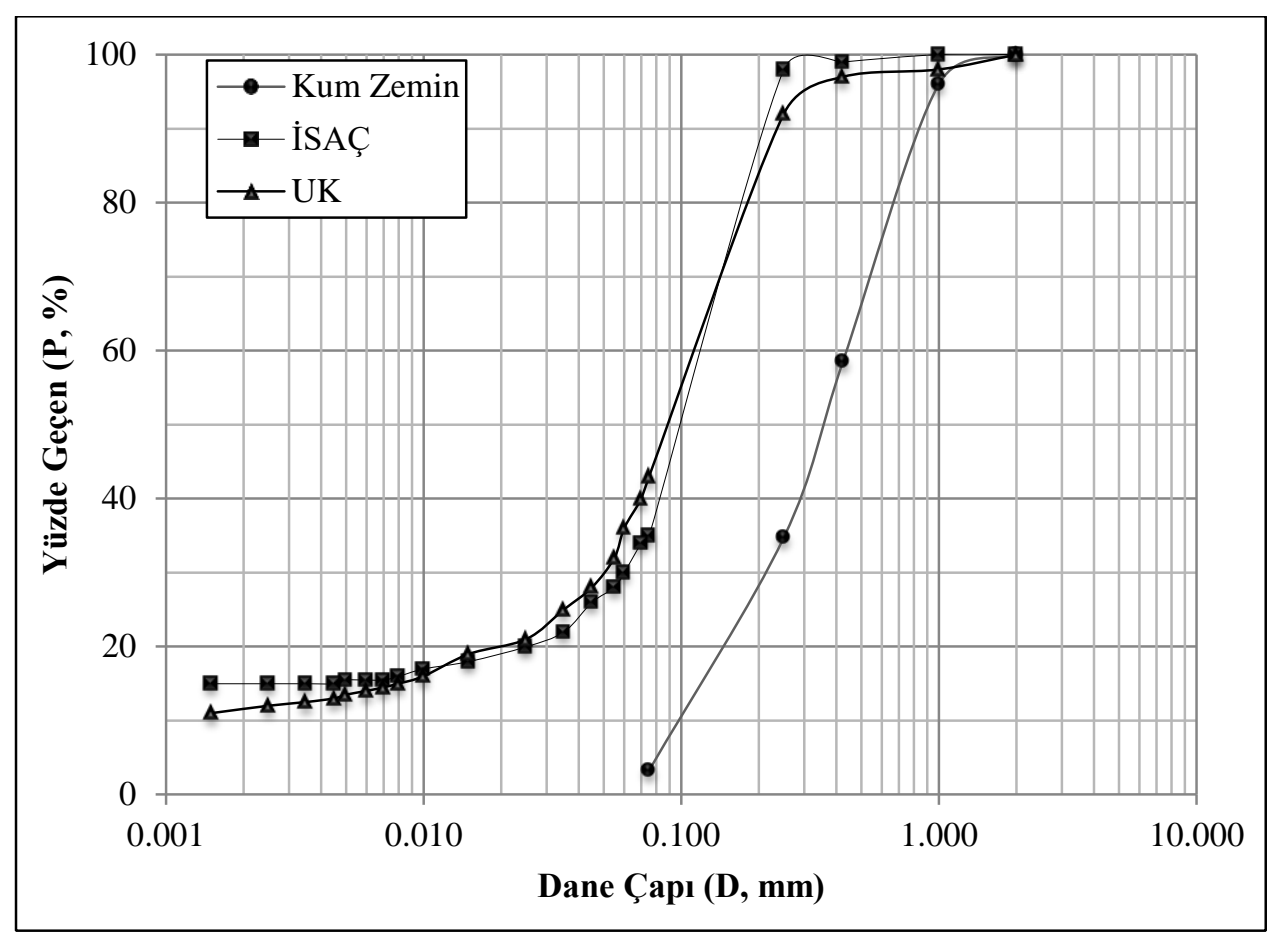

Şekil 1: Kullanılan Katkı Malzemelerinin ve Kumun Dane Boyutu Dağııı Eğrisi

Kumlu zeminin ve kumlu zeminin permeabilite özelliklerinin farklı katkı malzemeleri ile değişimini belirlemek amacıyla kullanılan UK ve İSAÇ'ın, X-1şınları difraksiyonu (XRD) yardımıyla elde edilen kimyasal içerikleri sırasıyla Tablo 1'deverilmiştir.Çalışmada kullanılan ve Tablo 1'de kimyasal özellikleri deneysel olarak belirlenen İSAÇ ve UK sırasıyla Adana ilinde bulunan içme suyu arıtma tesisi ve termik santralden temin edilmiştir.

Tablo 1: Kullanılan Katkı Malzemelerinin ve Kumun Kimyasal Özellikleri

\begin{tabular}{|c|c|c|c|}
\hline Birleşim (Ağırlıkça \%) & $\begin{array}{c}\text { Kumlu } \\
\text { Zemin }\end{array}$ & UK & íSAÇ \\
\hline $\mathrm{SiO}_{2}$ & 96.15 & 56.20 & 16.02 \\
\hline $\mathrm{Fe}_{2} \mathrm{O}_{3}$ & 2.10 & 25.40 & 48.23 \\
\hline $\mathrm{Al}_{2} \mathrm{O}_{3}$ & 0.6 & 6.10 & 2.62 \\
\hline $\mathrm{CaO}$ & 0.04 & 3.24 & 8.10 \\
\hline $\mathrm{K}_{2} \mathrm{O}$ & 0.22 & 3.07 & 0.31 \\
\hline $\mathrm{MgO}$ & 0.39 & 1.40 & 1.15 \\
\hline $\mathrm{NaO}_{2}$ & 0.07 & 1.29 & 0.30 \\
\hline $\mathrm{TiO}_{2}$ & - & - & 0.53 \\
\hline $\mathrm{P}_{2} \mathrm{O}_{5}$ & - & - & 0.13 \\
\hline $\mathrm{MnO}$ & - & - & 0.38 \\
\hline $\mathrm{ZnO}$ & - & - & 1.12 \\
\hline $\mathrm{K}$.zma $\mathrm{Kayb}$ (LOI) & & & 21.11 \\
\hline
\end{tabular}

\subsection{Metot}

Deneylerde kullanılan kumun en iyi şekilde sıkışmasının sağlanabilmesi amacıyla, optimum su muhtevasını belirlemek için proktor deneyi yapılmıştır. Çalışmada, ilk olarak sadece kumlu zemin olması durumunda, zeminin permeabilitesi değeri belirlemiştir. Daha sonra kumlu zemin içine sırasıyla UK ve İSAÇ karışımlarının permeabiliteye etkisinin araştırılabilmesi amacıyla, kum zemin içerisine ağırlıkça $\% 2, \% 4, \% 6, \% 8, \% 10, \% 12 \% 14, \% 16, \% 18, \% 20$ ve \%22 olacak şekilde karışım yapıldı. Bu karışımlardaki numunelere düşen seviyeli permeametre deneyi yapılarak, permeabilite değerleri belirlenmiştir. Deneyler TS 1900-I standardına (URL-4 2006) uygun olarak gerçekleştirilmiştir. Permeabilite deneyi sırasında çeşitli zamanlarda okumalar alınmış ve ortalaması alınarak permeabilite katsayıları hesaplanmıştır. Yapılan deneylere ait sembolik deney şeması Şekil 2'de gösterilmiştir. 

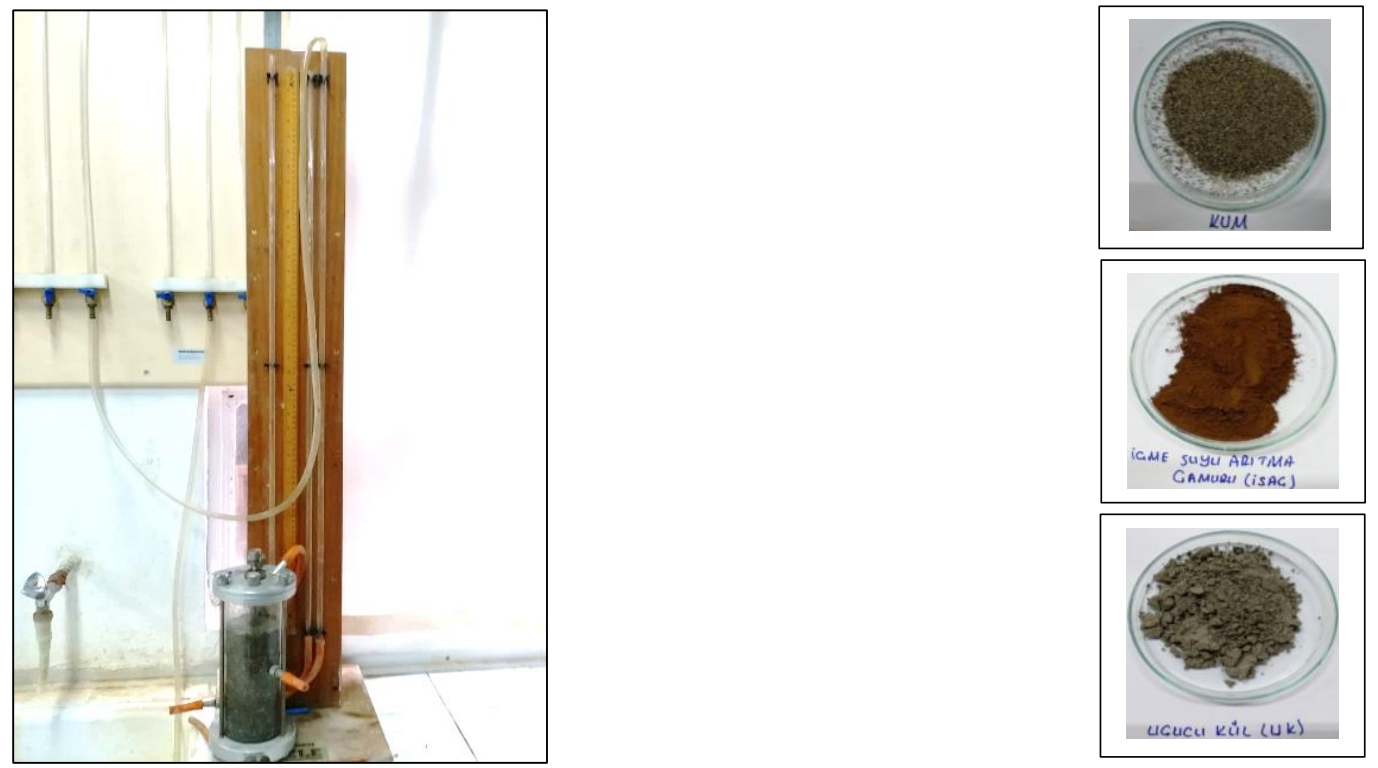

Şekil 2: Permeabilite Deney Düzeneği ve Kum Zemin-ISAÇ-UK

\section{Bulgular ve Tartışma}

UK ve İSAÇ karışımlarının permeabiliteye etkisinin belirlenebilmesi amacıyla, kum zemin içerisine ağırlıç̧a \%2, \% 4, $\%$ 6, \% 8, \% 10, \% $12 \%$ 14, \% 16, \% 18, \% 20 ve \% 22 olacak şekilde karışımlar yapılarak deneyler yapılmış ve sonuçları Tablo 3, Şekil3 ve Şekil 4'te gösterilmiştir. Deney boyunca alınan okumalar ve hesaplanan permeabilite katsayıları, zeminin doyurulması aşamasındaki değerleri içermemektedir.

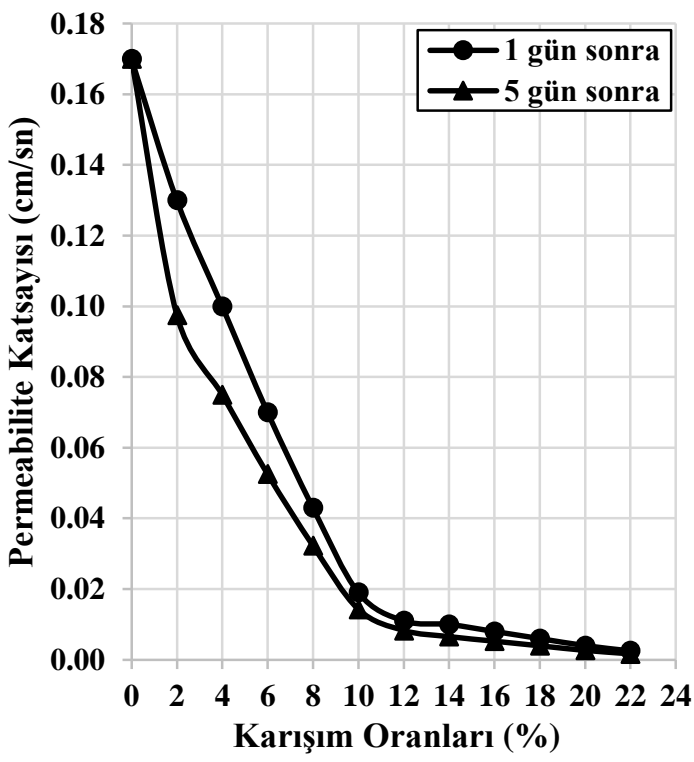

(a)İSAÇ

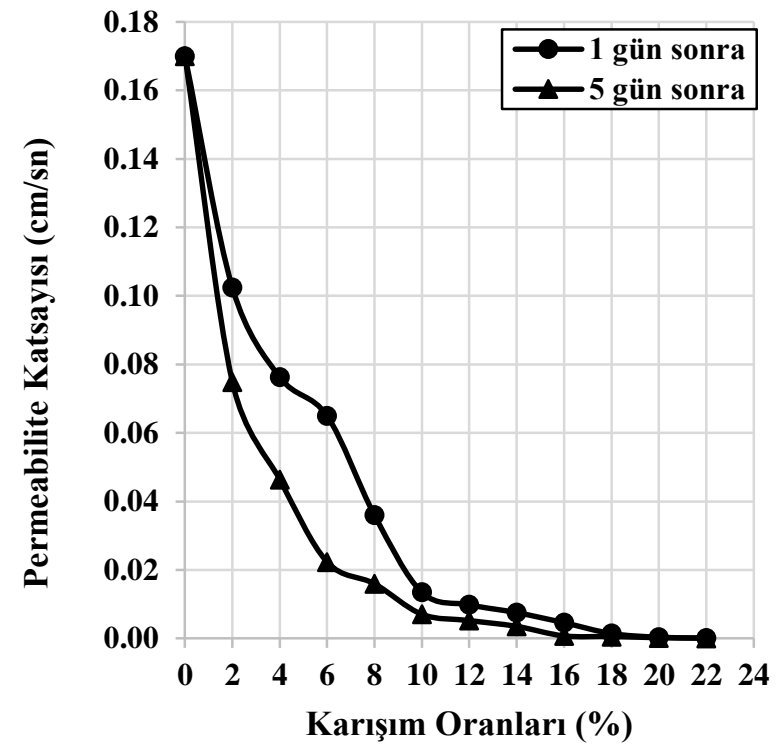

(b)UK

Şekil 3: Farklı Karışım ve Farklı Günlerdeki Permeabilite Değerleri 


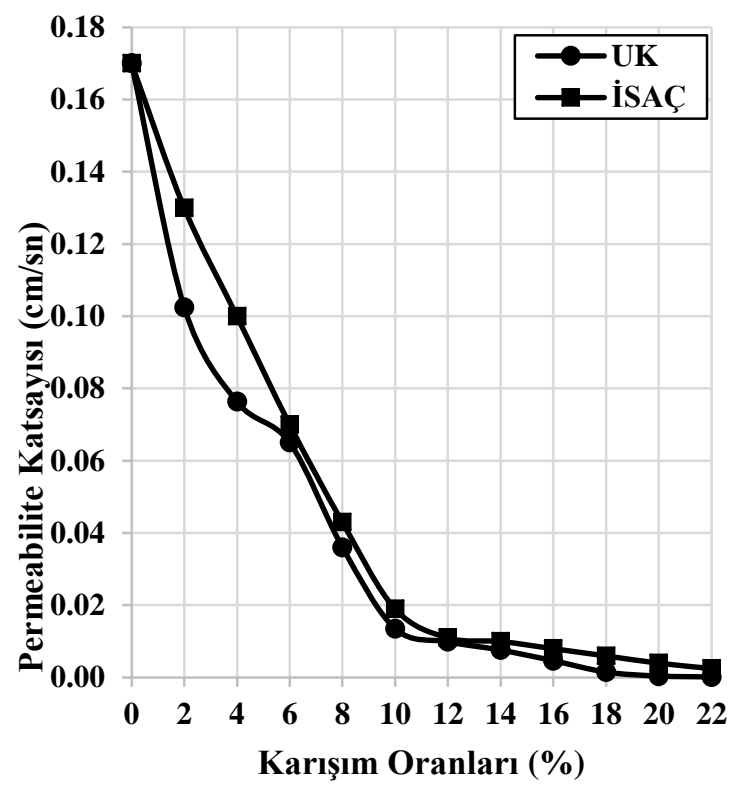

(a) 1 gün sonra

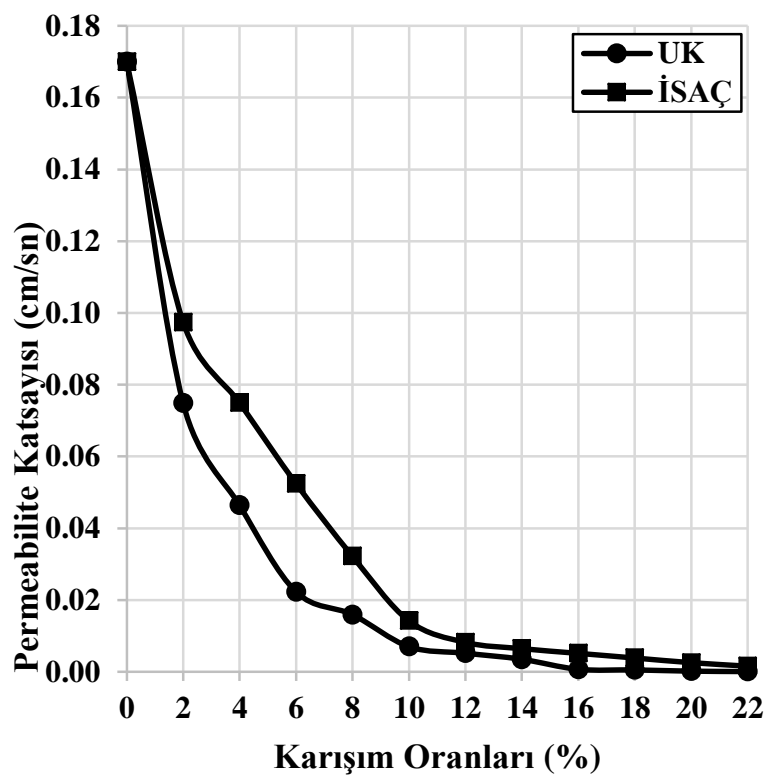

(b) 5 gün sonra

Şekil 4: Farklı Karışım ve Farklı Atık Malzemelerin Permeabilite Değerleri

Tablo 3: Permeabilite Değerleri

\begin{tabular}{|c|c|c|c|c|}
\hline & \multicolumn{2}{|c|}{ iSAÇ } & \multicolumn{2}{c|}{ UK } \\
\hline $\begin{array}{c}\text { Karışım } \\
\text { Oranı } \\
\text { \% }\end{array}$ & $\mathbf{1}$ gün sonra & 5 gün sonra & 1 gün sonra & 5 gün sonra \\
\hline 0 & \multicolumn{4}{|c|}{$\mathbf{~ c m ~ / ~ s n ~}$} \\
\hline 2 & $1.700 \times 10^{-1}$ & $1.700 \times 10^{-1}$ & $1.700 \times 10^{-1}$ & $1.700 \times 10^{-1}$ \\
\hline 4 & $1.300 \times 10^{-1}$ & $9.750 \times 10^{-2}$ & $1.025 \times 10^{-1}$ & $7.486 \times 10^{-2}$ \\
\hline 6 & $1.000 \times 10^{-1}$ & $7.500 \times 10^{-2}$ & $7.631 \times 10^{-2}$ & $4.645 \times 10^{-2}$ \\
\hline 8 & $7.000 \times 10^{-2}$ & $5.250 \times 10^{-2}$ & $6.500 \times 10^{-2}$ & $2.233 \times 10^{-2}$ \\
\hline 10 & $4.300 \times 10^{-2}$ & $3.230 \times 10^{-2}$ & $3.600 \times 10^{-2}$ & $1.596 \times 10^{-2}$ \\
\hline 12 & $1.900 \times 10^{-2}$ & $1.430 \times 10^{-2}$ & $1.350 \times 10^{-2}$ & $7.052 \times 10^{-3}$ \\
\hline 14 & $1.100 \times 10^{-2}$ & $8.250 \times 10^{-3}$ & $9.850 \times 10^{-3}$ & $5.224 \times 10^{-3}$ \\
\hline 16 & $1.000 \times 10^{-2}$ & $6.500 \times 10^{-3}$ & $7.560 \times 10^{-3}$ & $3.533 \times 10^{-3}$ \\
\hline 18 & $8.000 \times 10^{-3}$ & $5.200 \times 10^{-3}$ & $4.620 \times 10^{-3}$ & $7.346 \times 10^{-4}$ \\
\hline 20 & $6.000 \times 10^{-3}$ & $3.900 \times 10^{-3}$ & $1.458 \times 10^{-3}$ & $5.665 \times 10^{-4}$ \\
\hline 22 & $4.000 \times 10^{-3}$ & $2.600 \times 10^{-3}$ & $3.650 \times 10^{-4}$ & $2.167 \times 10^{-4}$ \\
\hline & $2.500 \times 10^{-3}$ & $1.630 \times 10^{-3}$ & $1.250 \times 10^{-4}$ & $1.005 \times 10^{-4}$ \\
\hline
\end{tabular}

Kum zeminden oluşturulmuş numunede permeabilite değeri gerek 1 gün sonra gerekse de 5 gün sonra yapılan ölçümler sonrasında $1.700 \times 10^{-1} \mathrm{~cm} / \mathrm{sn}$ olarak belirlenmiştir. Buradan sadece kum zemin olması durumunda ve kumun iç yapısında herhangi bir değişim olmadığı için zamana bağlı olarak permeabilite değerinde bir değişim olmadığı belirlenmiştir. Ayrıca, kumlu zemin içine farklı katkı oranlarında İSAÇ ve UK eklenmesi durumunda permeabilite değerlerinde kayda değer azalmalar meydana gelmiştir. İSAÇ’nin farklı oranlarda kum zemin içine eklenerek oluşturulan karışımın permeabilite değerleri incelendiğinde; 1 . günün sonunda yapılan deneylere göre ağırlıkça \% 2 oranında $1.300 \times 10^{-1} \mathrm{~cm} / \mathrm{sn}$ permeabilite değeri ölçülürken ağırlıkça $\% 22$ oranında $2.500 \times 10^{-3} \mathrm{~cm} / \mathrm{sn}$ permeabilite değeri ve 5 . günün sonunda yapılan deneylere göre ise ağırlıkça $\% 2$ oranında $9.750 \times 10^{-2} \mathrm{~cm} / \mathrm{sn}$ permeabilite değeri ölçülürken ağırlıç̧a $\% 22$ oranında $1.630 \times 10^{-3} \mathrm{~cm} / \mathrm{sn}$ permeabilite değeri elde edilmiştir. İSAÇ kullanımı ile 1.gün ve 5.günün sonunda sadece kum zeminin permeabilite değerine göre, permeabilite değerlerinde sırasıyla 68 ve 104 kata varan azalmalar meydana geldiği ve söz konusu zemin malzemesinin geçirimsizliğinin kayda değer bir şekilde arttığ1 görülmüştür (Şekil 3 a). Aynı şekilde UK kullanılması sonunda ise, 1.günün sonunda yapılan deneylere göre ağırlıça \%2 oranında $1.025 \times 10^{-1} \mathrm{~cm} / \mathrm{sn}$ permeabilite değeri ölçülürken ağırlıkça $\% 22$ oranında $1.250 \times 10^{-4} \mathrm{~cm} / \mathrm{sn}$ permeabilite değeri ve 5.günün sonunda yapılan deneylere göre ağırlıkça \%2 oranında $7.486 \times 10^{-2} \mathrm{~cm} / \mathrm{sn}$ permeabilite değeri ölçülürken ağırlıkça \%22 oranında $1.005 \times 10^{-4} \mathrm{~cm} / \mathrm{sn}$ permeabilite değeri elde edilmiştir. 
UK kullanımı ile 1. gün ve 5. günün sonunda permeabilite değerlerinde sırasıyla 1360 ve 1691 kata varan azalmalar meydana geldiği ve söz konusu zemin malzemesinin geçirimsizliğinin kayda değer bir şekilde arttığı görülmüştür (Şekil 3b). Diğer oranlarda ise, gerek İSAÇ gerekse de UK için genellikle ağırlıkça \%2 ile \%22 oranları arasında ölçülen permeabilite değerlerinin arasında kalan değerler elde edilmiştir. 1. günün ve 5. günün sonunda İSAÇve UK ile yapılan karışımlarla oluşturulan zeminin permeabilitesi hesaplandığı zaman ise, her iki günün sonunda UK ile yapılan karışımlarla oluşturulan kum zeminin permeabilite değerlerin de İSAÇ'a göre sırasıyla 20 ve 16 kata varan permeabilite değerlerinde düşüşler gözlenmiştir (Şekil 4). Çeşitli atık malzemeler ile muamele edilmiş zemin numuneleri üzerinde mekanik performans deneyleri yapılarak bu malzemelerin zemin iyileştirmede kullanılabilirliği araştırılmıştır. Orakoğlu ve Ekinci (2013), fiziksel özellikleri belirlenen zeminlerin permeabilite katsayısının belirlenmesi üzerine çalışmalar yapmışlardır. $\mathrm{Bu}$ çalışma sonucuna göre, kum ve silt oranları yüksek siltli veya killi ince kum zeminde, permeabilite katsayısı zemin doygunluğa ulaştıktan sonra ortalama olarak $1,728 \times 10^{-5} \mathrm{~cm} / \mathrm{sn}$ olarak belirlenmiştir. Lin vd. (2007) yaptıkları çalışmalarında, atık su arıtma tesisinden elde edilen çamurun $800^{\circ} \mathrm{C}$ yakılmasıyla oluşan kül ve UK atık maddelerin doğal zeminde meydana getirdiği değişimleri karşılaştırmışlardır. Gerçekleştirilen çalışmada, atık çamur küllü (\%5, \%2, \%4, $\% 8, \% 16$ oranlarında) ve UK ile muamele edilmiş zemin numuneleri üzerinde $\mathrm{pH}$ değeri, sıkıştırma, kaliforniya taşıma oranı basınç dayanımı ve üç eksenli sıkıştırma gibi test sonuçları karşılaştırılmıştır. Sonuçlar, çamuru külünün, yumuşak toprağın geliştirilmesinde UK'nın yerini alabileceğini göstermiştir. Taş vd. (2018), \%25 UK'ya , \%0, \%5, \%10, \%15, \%20 oranlarında tüf taş grubunda yer alan Bayburt taşı ilave ederek zemin stabilizasyonunda kullanılabilirliği incelenmiştir. Çalışmadaki sonuçlara göre, Bayburt taşı ve UK içeren karışımların yalnızca UK içeren karışımlara göre daha yüksek dayanım sonuçları meydana getirdiği tespit edilmiştir. Silitonga vd. (2009), deniz, göl gibi çökelen zeminlerin UK, çimento ve kireç ile stabilizasyon sonunda oluşan tane mekanik davranışı incelenmiştir. Bu çalışma sonucu çökelti malzemesi için UK-kireç-çimento birleşiminin kullanılabileceği belirtilmiştir. Brooks (2009), UK ile pirinç kabuğu külünün şişen zeminin dayanım özellikleri açısından kullanılmasını incelemişlerdir. Çalışmalarında, şişen zeminde \%12 pirinç kabuğu külü ve \%25 UK oranlarında en iyi dayanımı sağladığı tespit edilmiştir. Bağrıaçık vd. (2019), cam elyaf takviyeli kompozit boru üretiminde ortaya çıkan atık boru tozunun zeminlerde kullanımında zemin permeabilite değerleri üzerinde etkilerini incelemişlerdir. Çalışmada, kum zemin içerisine ağırlıça \%2, \% 4, \% 6, \% 8, \% 10, \% 12 \% $14, \% 16, \% 18, \% 20$ ve \% 22 oranlarında atık boru tozu ikameli karışımlar yapılarak permeabilite deneyleri yapılmıştır. Araştırmacılar atık boru tozu ilavesinin \%22 oranında olması durumunda saf kum ile oluşturulmuş zemine göre permeabilite değerinde 19 kata varan azalma tespit etmişlerdir.

\section{Sonuçlar ve Tartışma}

İSAÇ, içme suyu arıtma tesislerinde su arıtımı sırasında çıkan katı atıktır. UK ise termik santrallerde kömür yakılması sırasında oluşan ve baca gazlarında tutulan taneciklerden oluşmaktadır. Gelişen endüstri ve artan nüfusa paralel olarak hızla artan miktarda İSAÇ ve UK üretilmektedir. Böylece bu endüstriyel atıkların alternatif yöntemlerle değerlendirilmesi konusu çok daha fazla önem kazanmıştır. Bu çalışmada, İSAÇ ile UK'nın gevşek zemin ortamı içine ilave edilerek kısa süreli zamana bağlı geçirimlilik davranışı küçük ölçekli model deneyler yardımı ile araştırılmıştır. UK ve İSAÇ karışımlarının permeabiliteye etkisinin belirlenebilmesi amacıyla, kum zemin içerisine ağırlıça \%2, \%4, \%6, \%8, \%10, $\% 12 \% 14, \% 16, \% 18, \% 20$ ve \%22 olacak şekilde karışımlar yapılarak deneyler yapılmış ve sonuçlar aşağıda özetlenmiştir.

- Deney boyunca alınan okumalar ve hesaplanan permeabilite katsayıları, zeminin doyurulması aşamasındaki değerleri içermemektedir.

- Kumdan oluşturulmuş numunede permeabilite değeri yapılan tüm deneyler için $1.700 \times 10^{-1} \mathrm{~cm} / \mathrm{sn}$ olarak belirlenmiştir.

- ISAÇ’ın farklı oranlarda kum zemin içine eklenerek oluşturulan karışımın permeabilite değerleri incelendiğinde; 1. günün sonunda yapılan deneylere göre ağırlıça $\% 2$ oranında $1.30 \times 10^{-1} \mathrm{~cm} / \mathrm{sn}$ permeabilite değeri ölçülürken ağırlıkça \%22 oranında $2.500 \times 10^{-3} \mathrm{~cm} / \mathrm{sn}$ permeabilite değeri ve 5 . günün sonunda yapılan deneylere göre ağırlıkça $\% 2$ oranında $9.750 \times 10^{-2} \mathrm{~cm} / \mathrm{sn}$ permeabilite değeri ölçülürken ağırlıkça $\% 22$ oranında $1.630 \times 10^{-3} \mathrm{~cm} / \mathrm{sn}$ permeabilite değeri elde edilmiştir. \%22 İSAÇ içeren kumlu zeminde tüm günlerin sonunda yapılan deneylerde kayda değer oranlarda (104 kata varan) permeabilite değerlerinde azalmaların meydana geldiği, dolayısıyla geçirimsizliğin arttı̆̆ belirlenmiştir.

- UK kullanılması sonunda ise, 1.günün sonunda yapılan deneylere göre ağırlıkça \%2 oranında $1.025 \times 10^{-1} \mathrm{~cm} / \mathrm{sn}$ permeabilite değeri ölçülürken ağırlıkça $\% 22$ oranında $1.050 \times 10^{-4} \mathrm{~cm} / \mathrm{sn}$ permeabilite değeri ve 5 . günün sonunda yapılan deneylere göre ağırlıkça $\% 2$ oranında $7.486 \times 10^{-2} \mathrm{~cm} / \mathrm{sn}$ permeabilite değeri ölçülürken ağırlıça $\% 22$ oranında $2.187 \times 10^{-4} \mathrm{~cm} / \mathrm{sn}$ permeabilite değeri elde edilmiştir. \%22 UK kullanımı yapılan karışımda tüm günlerin sonunda yapılan deneylerde kayda değer oranlarda (1691 kata varan) kum zeminde permeabilite değerlerinde azalmaların meydana geldiği, dolayısıyla geçirimsizliğin arttığı belirlenmiştir.

- Hem İSAÇ hem de UK karışımları için geçirimlilik değerlerinde lineer olmayan bir azalmanın meydana geldiği belirlenmiştir. Yaklaşık \%10 karışım oranlarına kadar, permeabilite değerlerinde daha hızlı azalma meydana gelirken, bu orandan sonraki değerlerde ise permeabilite değerlerindeki azalma hızlarının daha az olduğu belirlenmiştir. 
- $\quad \% 2$ ila \%22 arasında İSAÇ ve UK ile yapılan karışımlarla oluşturulan zeminin permeabilitesi hesaplandığg zaman ise, her iki günün sonunda UK ile yapılan karışımlarda tüm oranlarda permeabilite değerlerin de 16-20 kata varan oranlarda daha düşük çıktığ 1 görülmüştür.

Sonuç olarak UK ve İSAÇ endüstriyel atık malzemelerin farklı projeler için tasarlanabilecek kumlu zeminlerde geçirgenlik değerinin azaltılabileceğinin mümkün olduğu belirlenmiştir. Ayrıca bu atıkların yeniden kullanımı ile atık yönetimi açısından da faydalı bir yaklaşım olarak değerlendirilebileceği ortaya konulmuştur. Atık boru tozu kullanılarak, kötü derecelenmiş kum zeminlerin permeabilitesinin azaltılması ile bu tür zeminlerin donma ve çözünme özelliklerinin de azalan permeabiliteden dolayı iyileşebileceği düşünülmektedir.

\section{Kaynaklar}

Ahmad T., Ahmad K., Alam M., (2016), Sustainable management of water treatment sludge through 3 ' $R$ 'concept, Journal of Cleaner Production, 124, 1-13.

Ahmaruzzaman M., (2010), A review on the utilization of fly ash, Progress in energy and combustion science, 36(3), 327-363.

Aldaood A., Bouasker M., Al-Mukhtar M., (2014),Free swell potential of lime-treated gypseous soil, Applied Clay Science, 102, $93-$ 103.

Amin S.K., Hamid E.A., El-Sherbiny S., Sibak H., Abadir M., (2018), The use of sewage sludge in the production of ceramic floor tiles, HBRC Journal, 14(3), 309-315.

Bağrıaçık B., Güner E.D., Beycioğlu A., (2019), Atık boru tozunun kum zeminlerin permeabilite değerleri üzerindeki etkileri, Artıbilim: Adana Alparslan Türkeş Bilim ve Teknoloji Üniversitesi Fen Bilimleri Dergisi, 2(1), 6-13.

Basu M., Pande M., Bhadoria P., Mahapatra S., (2009), Potential fly-ash utilization in agriculture: a global review, Progress in Natural Science, 19(10), 1173-1186.

Benlalla A., Elmoussaouiti M., Dahhou M., Assafi M., (2015), Utilization of water treatment plant sludge in structural ceramics bricks, Applied Clay Science, 118, 171-177.

Brooks R.M., (2009), Soil Stabilization with Fly Ash and Rice Husk Ash, Int. Journal of Research and Reviews in Applied Sciences, 1(3), 209-217.

Caniani D., Masi S., Mancini I., Trulli E., (2013), Innovative reuse of drinking water sludge in geo-environmental applications, Waste management, 33(6), 1461-1468.

Cristelo N., Glendinning S., Fernandes L., Pinto A.T., (2013), Effects of alkalineactivated fly ash and Portland cement on soft soil stabilisation, Acta Geotech, 8(4), 395-405.

Dabhade A.N., Chaudari S.R., Gajbhaye A.R., (2014), Effect of fly ash on recycle coarse aggregate concrete, Int. J. Civ. Eng. Res, (5), 2278-3652.

Dassanayake K., Jayasinghe G., Surapaneni A., Hetherington C., (2015), A review on alum sludge reuse with special reference to agricultural applications and future challenges, Waste Management, 38, 321-335.

Dindi A., Quang D.V., Vega F.L., Nashef E., Abu-Zahra M.R.M., (2019), Review Article Applications of fly ash for CO 2 capture, utilization, and storage, Journal of $\mathrm{CO}_{2}$ Utilization, 29, 82-102.

Feng Y., Zhang Y., Quan X., Chen S., (2014), Enhanced anaerobic digestion of waste activated sludge digestion by the addition of zero valent iron, Water research, (52), 242-250.

Frías M., De La Villa R.V., De Soto I., Garcia R., Baloa T., (2014), Influence of activated drinking-water treatment waste on binary cement-based composite behavior: Characterization and properties, Composites Part B: Engineering, 60, 14-20.

Garrido-Baserba M., Molinos-Senante M., Abelleira-Pereira J.M., Fdez-Güelfo L.A., Poch M., Hernández-Sancho F., (2015), Selecting sewage sludge treatment alternatives in modern wastewater treatment plants using environmental decision support systems, Journal of Cleaner Production, 107, 410-419.

Ghazawi Z., Khedaywi T., Gouneem A., (2015), Pollution reduction and reuse of sludge waste in asphalt paving mixtures, Proceedings of the 4th International Conference on Energy Systems, Environment, Entrepreneurship and Innovation (ICESEEI'15), February 22-24, Dubai, United Arab Emirates.

González A., Navia R., Moreno N., (2009), Fly ashes from coal and petroleum coke combustion: current and innovative potential applications, Waste Manag. Res., 27, 976-987.

Hacısalihoğlu N., (2008), Farklı Sıcaklıklarda Aktifleştirilmiş İçme Suyu Arıtma Çamurunun Çimentoda Kullanılabilirliğini Araştırılması, Yüksek Lisans Tezi, Karadeniz Teknik Üniversitesi Fen Bilimleri Enstitüsü, Trabzon.

Hadi M.N.S., Al-Azzawi M., Yu T., (2018), Effects of fly ash characteristics and alkaline activator components on compressive strength of fly ash-based geopolymer mortar, Construction and Building Materials, (175)30, 41-54.

Hu S.H., Hu S.C., Fu Y.P., (2013), Recycling technology—artificial lightweight aggregates synthesized from sewage sludge and its ash at lowered comelting temperature, Environmental Progress \& Sustainable Energy, 32(3), 740-748.

Jensen J., Jepsen S.E., (2005), The production, use and quality of sewage sludge in Denmark, Waste Management, 25(3), $239-247$.

Jung K.W., Hwang M.J., Park D.S., Ahn K.H., (2016), Comprehensive reuse of drinking water treatment residuals in coagulation and adsorption processes, Journal of environmental management, 181, 425-434.

Lin, D.F., Lin K.L.,Luo H.L., (2007), A Comprasion between Sludge Ash and Fly Ash on the Improvement in Soft Soil, Journal of the Air-Waste Management Assocition, 57, 59-64

Mahvash S., López-Querol S., Bahadori-Jahromi A., (2017), Effect of class F fly ash on fine sand compaction through soil stabilization, Heliyon, 3(3), E00274:1-27.

Mazzoli A., Moriconi G., (2014), Particle size, size distribution and morphological evaluation of glass fiber reinforced plastic (GRP) industrial by-product, Micron, 67, 169-178.

Nath P., Sarker P., (2011), Effect of fly ash on the durability properties of high strength concrete, Procedia Eng., 14, $1149-1156$.

Nimwinya E., Arjharn W., Horpibulsuk S., Phoo-ngernkham T., Poowancum A., (2016), A sustainable calcined water treatment sludge and rice husk ash geopolymer, Journal of Cleaner Production, 119, 128-134. 
Orakoğlu M.E., Ekinci C.E., (2013),Zeminlerin permeabilite katsayısı ve konsolidasyon özellikleri üzerine bir çalışma: Elazı̆̆ örneği, Uluslararası Teknolojik Bilimler Dergisi,5(1), 44-50.

Ren X., Sancaktar E., (2019), Use of fly ash as eco-friendly filler in synthetic rubber for tire applications, Journal of Cleaner Production, 206(1), 374-382.

Rodríguez N.H., Martinez-Ramirez S., Blanco-Varela M., Guillem M., Puig J., Larrotcha E., Flores J., (2011), Evaluation of spraydried sludge from drinking water treatment plants as a prime material for clinker manufacture, Cement and Concrete Composites, 33(2), 267-275.

Santana M.V., Zhang Q., Mihelcic J.R., (2014), Influence of water quality on the embodied energy of drinking water treatment, Environmental science \& technology, 48(5), 3084-3091.

Santos F., Li L., Li Y., Amini F., (2011), Geotechnical Properties of Fly Ash and soil mixtures for use in highway embankments, World of Coal Ash (WOCA) Conference, May 9-12, Denver, USA.

Silitonga E., Levacher D., Mezazigh S., (2009), Effects of the Use of Fly Ash as a Binder on the Mechanical Behaviour of Treated Dredged Sediments, Environmental Technology, 30(8), 799-807.

Sun Z., Vollpracht A., (2019), One year geopolymerisation of sodium silicate activated fly ash and metakaolin geopolymers, Cement and Concrete Composites, 95, 98-110.

Tantawy M.A., (2015), Characterization and pozzolanic properties of calcined alum sludge, Materials Research Bulletin, 61, 415421.

Tosun H., (1999),Sulama kanallarında görülen şişen zemin problemleri ve inşaat önlemleri, Osmangazi Üniversitesi Müh. Mim. Fak. Dergisi, XII(1), 23-44.

Taş M., Fidan D., Yılmaz F., (2018), Uçucu Kül ve Bayburt Taşı ile Zemin Stabilizasyonu, Bayburt Üniversitesi Fen Bilimleri Dergisi, $1(1), 8-14$.

TÜİK, (2019), Belediye Atıksu İstatistikleri, Türkiye İstatistik Kurumu,https://biruni.tuik.gov.tr/medas/?kn=120\&locale=tr, [Erişim 25 Şubat 2019].

URL-1, (1991), Council Directive of 21 May 1991 Concerning Urban Waste Water Treatment 91/271/EEC, L 135/40, https://eurlex.europa.eu/legal-content/EN/TXT/PDF/?uri=CELEX:31991L0271\&from=EN, [Erişim 20 Ekim 2019].

URL-2, (1999), Council Directive 1999/31/EC of 26 April 1999 on the Landfill of Waste, L182, https://eur-lex.europa.eu/legalcontent/EN/TXT/PDF/?uri=CELEX:31999L0031\&from=EN, [Erişim 20 Ekim 2019].

URL-3, (2000), Türk Standardı TS 1500, İnşaat Mühendisliğinde Zeminlerin Sinıflandırılması, https://docplayer.biz.tr/18847271-Turkstandardi-turkish-standard.html, [Erişim 12 Kasım 2019].

URL-4, (2006), Türk Standardı TS 1900-I, Inşaat Mühendisliğinde Zemin Laboratuvar Deneyleri - Bölüm 1: Fiziksel Özelliklerin Tayini, http://depo.osmaniye.edu.tr/dosyalar/Dosyalar/TS\%201900-1\%281\%29.pdf, [Erişim 12 Kasım 2019].

Uzuner B.A., (2000), Temel mühendisliğine giriş, Derya Kitabevi, Trabzon, 306ss.

Velasco P.M., Ortíz M.M., Giró M.M., Velasco L.M., (2014), Fired clay bricks manufactured by adding wastes as sustainable construction material-A review, Construction and Building materials, 63, 97-107.

Wang M., Hull J., Jao M., Dempsey B., Cornwell D., (1992), Engineering behavior of water treatment sludge, Journal of Environmental Engineering, 118 (6), 848-864.

Xie J., Wang J., Rao R., Wang C., Fang C., (2019), Effects of combined usage of GGBS and fly ash on workability and mechanical properties of alkali activated geopolymer concrete with recycled aggregate, Composites Part B, 164 179-190.

Yang S.S., Guo W.Q., Chen Y.D., Wu Q.L., Luo H.C., Peng S.M., Zheng H.S., Feng X.C., Zhou X., Ren N.Q., (2015), Economical evaluation of sludge reduction and characterization of effluent organic matter in an alternating aeration activated sludge system combining ozone/ultrasound pretreatment, Bioresour Technol, 177, 194-203.

Yao Z.T., Ji X.S., Sarker P.K., Tang J.H., Ge L.Q., Xia M.S., Xi, Y.Q., (2015), A comprehensive review on the applications of coal fly ash, Earth-Science Reviews, (141), 105-121.

Zacco A., Borgese L., Gianoncelli A., StruisR.P.W.J., Depero L.E., Bontempi E., (2014), Review of fly ash inertisation treatments and recycling, Environ Chem Lett, 12(1), 153-175.

Zhang G., He J., Zhang P., Zhang J., (2009), Ultrasonic reduction of excess sludge from activated sludge system II: Urban sewage treatment, Journal of Hazardous Materials, 164(2-3), 1105-1109. 